\title{
Differential responding on reinforcement and nonreinforcement trials occurring in fixed repeating patterns'
}

\author{
A. Martin Wall, UNIVERSITY OF TORONTO \\ Kenneth P. Goodrich, UNIVERSITY of WISCONSIN
}

\begin{abstract}
Four rats were trained on each of three discretetrials schedules of reinforcement in which on eachtrial a bar-press was reinforced or not according to a fixed repeating pattern. Analysis of response latencies showed differences among all reinforcement and nonreinforcement trials within each schedule for each rat: latencies were shorter on nonreinforcement trials closer to the next reinforcement trial and shortest on the reinforcement trial.
\end{abstract}

\section{Problem}

A recursive schedule of reinforcement consists of a series of trials each of which provides the opportunity for a single response that is reinforced or not according to a fixed sequential pattern. For example, in a N2N1 schedule each reinforcement (R) trial follows two nonreinforcement $(\mathrm{N})$ trials in a recurring sequence, $\mathrm{N}_{1} \mathrm{~N}_{2} \mathrm{R}$. On each trial some measure of the response is obtained, and interest is focused on differences in this measure among the $\mathrm{N}$ and $\mathrm{R}$ trials.

Several experiments (e. g., Tyler et al., 1953) have demonstrated differential responding within a N1R1 (single alternation) schedule in groups of rats using measures of running time in a runway. After about 60 trials, rats ran more rapidly on $\mathrm{R}$ trials than on $\mathrm{N}$ trials. Experiments using the more complex N2R1 schedule (Capaldi \& Senko, 1962; Capaldi \& Hart, unpublished ${ }^{2}$ ) found that rats ran more slowly on $\mathrm{N}_{1}$ than on $\mathrm{R}$ trials, but that they failed to differentiate $\mathrm{N}_{2}$ and $\mathrm{R}$ trials.

Failure to find differential responding within a recursive schedule may imply insufficient training. In addition, intertrial removal of $\mathrm{S}$ from the runway may disrupt the temporal course of mediating events essential for differential response on successive trials in the recursive pattern. In the present experiment, rats underwent extended training in an automated apparatus on three recursive schedules, N1R1, N2R1, and N3R1.

\section{Method}

Data were obtained from four naive female hooded rats, about 150 days old, maintained at $80 \%$ of their free-feeding weights. The apparatus was a soundinsulated rat chamber with a retractable bar (Foringer No. 1222) and standard control equipment. A trial began every $30 \mathrm{sec}$. with the onset of a house light and the entrance of the bar. When the rat pressed the bar, or after $15 \mathrm{sec}$. without a bar-press, the trial terminated with the offset of the light and the retraction of the bar. On $\mathrm{R}$ trials, a bar-press yielded a dipperful (approx.
$0.05 \mathrm{cc}$ ) of sucrose solution ( $16 \%$ by weight) accompanied by a 5 -sec. light over the dipper. The latencies of barpresses were recorded on an Elmeg printing counter in units of $0.1 \mathrm{sec}$.

All rats were pretrained under free-operant CRF and then under discrete-trial CRF for 300 trials. They were subsequently trained under three recursive schedules in the order N1R1, N2R1, and N3R1 for Rats 1 and 3; and N2R1, N1R1, and N3R1 for Rats 2 and 4. All rats received a minimum of 1980 trials on the initial schedule; all received 1000 trials on the final two schedules. Daily sessions consisted of 300 to 800 trials.

\section{Hesults and Discussion}

Median latencies for the $\mathrm{N}$ and $\mathrm{R}$ trials in each schedule were calculated, for each rat separately, in successive blocks of 60 trials. Failures to respond were infrequent; in computing medians they were assigned latencies of $15 \mathrm{sec}$. Figure 1 depicts the course of responding during the initial recursive schedule following CRF. After a more or less prolonged period of equivalent latencies on $\mathrm{N}$ and $\mathrm{R}$ trials, a pattern of differential responding eventually emerged in all rats. This pattern is shown clearly in Fig. 2, which presents performance data on all three schedules. Although there were overall differences in the average latencies of the four rats, all animals exhibited in each schedule progressively shorter latencies on trials closer to the next reinforcement trial.

These results indicate that previous failures to obtain differentiation of $\mathrm{N}_{2}$ and $\mathrm{R}$ trials in runway situations

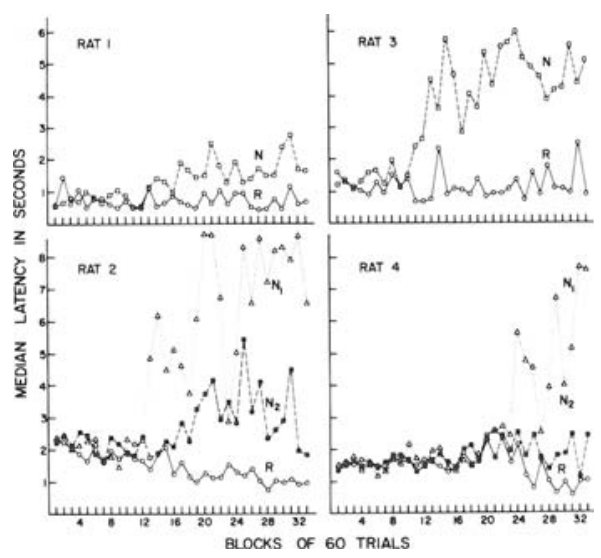

Fig. 1. Latencies on $\mathrm{N}$ and $\mathrm{R}$ trials under schedules N1R1 (Rats 1 and 3) and N2R1 (Rats 2 and 4). 


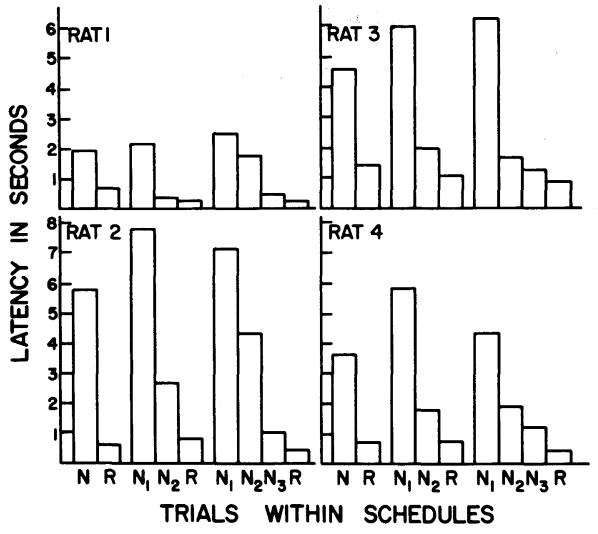

Fig. 2. Latencies on $\mathrm{N}$ and $\mathrm{R}$ trials for each rat over 360 trials on each schedule, Trials 1621-1980 for the initial schedule and Trials 641-1000 for the subsequent two schedules. Each value is the mean of six 60 -trial medians.

are attributable to limitations in experimental conditions and not to limitations in the rat. Because the present experiment and earlier experiments differed in several respects, the critical conditions are not presently identifiable.

An analysis in terms of "temporal discrimination" may prove helpful. It is noteworthy that in both the fixed-interval (FI) scallop in a free-operant situation (Ferster \& Skinner, 1957, pp. 133-325) and the data shown in Fig. 2, a time measure of performance decreases systematically as the time for the next rein- forcement approaches. The recursive schedules employed in the present study may be regarded as FI schedules with limited opportunity for nonreinforced responding. This analysis suggests that temporal mediating processes required for differentiation in recursive schedules may be disrupted by the intertrial procedures used in runway studies. It also corroborates data indicating that chained bar-presses are not required for the FI scallop (Dews, 1962; Wall, 1964).

\section{References}

CAPALDI, E. J., \& SENKO, M. G. Acquisition and transfer in partial reinforcement. J. exp. Psychol., 1962, $63,155-159$.

DEWS, P. B. The effect of multiple $\mathrm{S}^{\Delta}$ periods on responding on a fixed interval schedule. J. exp. Anal. Beh., 1962, 5, 369-374.

FERSTER, C. B., \& SKINNER, B. F. Schedules of reinforcement. New York: Appleton-Century-Crofts, 1957.

TYLER, D. W., WORTZ, E. C., \& BitTERMAN, M. E. The effect of random and alternating partial reinforcement on resistance to extinction in the rat. Amer. J.Psychol., 1953, 66, 57-65.

WALL, A. M. A discrete-trials analysis of fixed-interval discrimination. Unpublished doctoral dissertation, Univer. of Pennsylvania, 1964.

\section{Notes}

1. Supported by NIH Grant M-4426(A) to the University of Pennsylvania and NIH Grants MH-04528 and FR00167 to the University of Wisconsin.

2. Personal communication from E. J. Capaldi, University of Texas. 